\title{
Pre(peri)-natal $\omega$-3 PUFA deficiency-induced hypertension and its broader implications
}

\author{
Undurti N Das \\ Hypertension Research (2012) 35, 375-379; doi:10.1038/hr.2011.225; published online 19 January 2012
}

$\mathrm{E}$ ssential hypertension is common and is an important risk factor for coronary heart disease (CHD), stroke, atherosclerosis and peripheral vascular disease. Blood pressure progression is a strong and independent predictor of the occurrence of type 2 diabetes mellitus in hypertensive patients, ${ }^{1}$ suggesting a close link between diabetes and hypertension. It is estimated that hypertension affects approximately $20-25 \%$ of all adults above the age of 45-50 years, and it is common in overweight and obese subjects. Hence, a better understanding of the pathobiology of hypertension may help to develop effective strategies for the prevention and management of not only hypertension, but also of its associated conditions, such as obesity, type 2 diabetes mellitus and CHD. This is especially true in the light of the fact that increases in peripheral vascular resistance, insulin resistance and endothelial dysfunction and enhanced activity of the sympathetic nervous system are observed in obesity, type 2 diabetes mellitus and hypertension. ${ }^{2-11}$

Hypertension is characterized by an increase in peripheral vascular resistance that could be attributed to the loss or decrease in endothelium-dependent vasodilation. The endothelium produces vasoactive factors such as prostacyclin $\left(\mathrm{PGI}_{2}\right)$, nitric oxide (NO), endothelium-derived hyperpolarizing factor, endothelin and prostaglandin $\mathrm{E}_{1}\left(\mathrm{PGE}_{1}\right) \cdot{ }^{12-17}$ Under normal physiological conditions, a balance is maintained between vasoconstrictors and vasodilators to maintain

Dr UN Das is at the UND Life Sciences, 13800 Fairhill Road, \#321, Shaker Heights, OH 44120, USA or Jawaharlal Nehru Technological University, Kakinada533 003, India or Bio-Science Research Centre, Gayatri Vidya Parishad College of Engineering, Visakhapatnam -530048 , India.

E-mail: undurti@hotmail.com normal blood pressure. When this balance is tilted more in favor of vasoconstrictors, and/ or when the concentrations of vasodilators are reduced, hypertension will set in. There is evidence to suggest that free radicals, such as superoxide anion $\left(\mathrm{O}_{2}{ }^{-}\right)$and hydrogen peroxide $\left(\mathrm{H}_{2} \mathrm{O}_{2}\right)$, also have a significant role in the pathobiology of hypertension, partly by modulating the formation, half-life and action of NO, lipid peroxides and arachidonic acid (AA). Free radicals also modulate the formation, half-life and action of eicosapentaenoic acid (EPA) and docosahexaenoic acid (DHA) metabolites formed by the action of the cytochrome p450 enzyme system; these molecules include epoxyeicosatrienoic acids from AA, 20-hydroxypentaenoic acid (20HEPE) and 17,18-epoxyeicosatetraenoic acid (17,18-EETeTr) from EPA, and 22-hydroxydocosahexaenoic acid (22-HDHE) and 19,20epoxydocosapentaenoic acid (19,20-EDP) from $\mathrm{DHA}^{18-21}$ (see Figure 1, see Figure 2 for the metabolisms of AA, EPA and DHA).

In light of this evidence, it is interesting that Begg et al. ${ }^{22}$ reported in this issue that the expression of angiotensin- $\mathrm{II}_{1 \mathrm{~A}}$ receptors and dopamine D3 receptors was significantly increased in the hypothalamic tissue of $\omega-3-$ deficient animals at age 10 weeks, and the $\alpha 2 \mathrm{a}$ and $\beta 1$ adrenergic receptor expression was significantly reduced at 36 weeks in animals that developed hypertension in adult life as a result of having received an $\omega$-3-deficient diet during the prenatal period. This model of hypertension, developed by Weisinger et al., formed the basis of many studies by the same group. $^{23-27}$ This seems to be a good model in which to study the interaction between dietary fatty acids and hypertension, especially the role of $\omega-3$ fatty acids. The concept that prenatal deficiency of $\omega-3$ fatty acids leads to the development of adult-onset hypertension gains support from the observations that supplementation of $\omega$ - 3 fatty acids (especially EPA and DHA) reduces blood pressure in spontaneously hypertensive rats, ${ }^{28}$ and infants supplemented with $\omega-3$ fatty acids have lower blood pressures. ${ }^{29}$ Furthermore, breast milk consumption has been associated with lower blood pressure in later life, ${ }^{30-32}$ and this beneficial action could be due to the presence of significant amounts of PUFAs (polyunsaturated fatty acids) in human milk (AA > DHA > EPA; see Table 1 for the fatty acid composition of human breast milk). Breast-fed infants have a significantly higher percentage of PUFAs in their tissues compared with those who are fed formula, lending support to this assumption. ${ }^{33}$ In addition, both EPA and DHA suppress the development of hypertension in stroke-prone SHR, inhibit the activity of angiotensin-converting enzyme (ACE), and enhance the production of endothelial NO (eNO) generation, which may aid in their ability to lower blood pressure (reviewed in 34). Despite this evidence of the relationship between PUFAs (especially $\omega-3$ EPA and DHA) and blood pressure, several questions still remain.

The concept of prenatal $\omega-3$ deficiency leading to the development of adult-onset hypertension is not a true replica of the essential hypertension observed in adults, as these animals showed marginal increases in systolic pressure (although significant compared with the control group), but no significant increases in diastolic pressure at 36 weeks of age ( 10 weeks of age: systolic: $\omega-3$ DEF (w-3 PUFA deficient): $123.5 \pm 1.9 \mathrm{~mm} \mathrm{Hg}$, SUF-S (diet sufficient in short-chain omega-3 fatty acids $(7 \%$ safflower oil $+3 \%$ flaxseed oil)): $120.1 \pm 1.9 \mathrm{~mm} \mathrm{Hg}$, SUF-SL (diet sufficient in short- and long-chain omega-3 fatty acids $(7 \%$ safflower oil $+2.9 \%$ flaxseed 

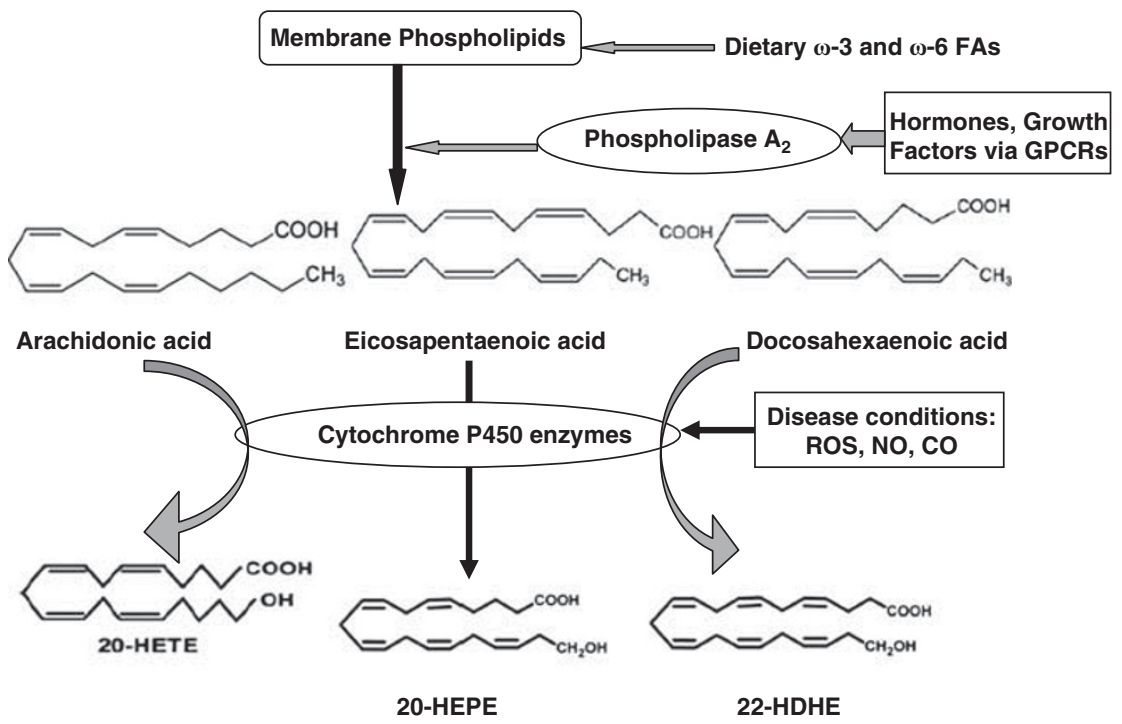

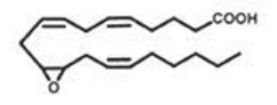

11, 12-EET

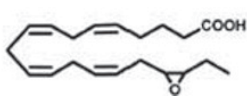

17, 18-EETeTr

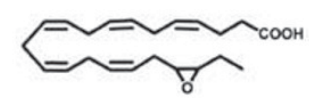

19,20-EDP

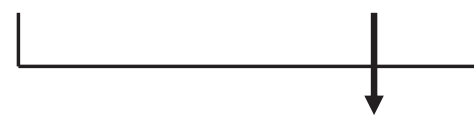

Regulation of Vascular, Renal and Cardiac Function

Figure 1 Scheme showing the formation of various products from AA, EPA and DHA due to the action of cytochrome p450.

oil + 0.1\% tuna oil)): $124.2 \pm 2.2 \mathrm{~mm} \mathrm{Hg}$; diastolic: $\omega-3$ DEF: $82.5 \pm 1.6 \mathrm{~mm} \mathrm{Hg}$, SUF-S: $81.3 \pm 1.2 \mathrm{~mm} \mathrm{Hg}$, SUF-SL: $82.1 \pm 1.5 \mathrm{~mm} \mathrm{Hg}$; 36 weeks of age: systolic: $\omega-3$ DEF: $149.4 \pm$ $3.7 \mathrm{~mm} \mathrm{Hg}$, SUF-S: $133.1 \pm 3.6 \mathrm{~mm} \mathrm{Hg}$, SUF-SL: $132.2 \pm 2.0 \mathrm{~mm} \mathrm{Hg}$; diastolic $\omega-3$ DEF: $87.9 \pm$ $2.7 \mathrm{~mm} \mathrm{Hg}$, SUF-S: $83.3 \pm 2.1 \mathrm{~mm} \mathrm{Hg}$, SUF-SL: $84.5 \pm 1.6 \mathrm{~mm} \mathrm{Hg}) .^{22}$ It is not known whether these $\omega-3$ DEF animals develop the complications observed in humans with essential hypertension, such as malignant hypertension, hypertensive retinopathy, atherosclerosis, stroke, CHD, cardiac failure, cardiac arrhythmias and renal failure. A study in this direction is needed.

Despite the fact that pre(peri-)natal $\omega-3$ deficiency could lead to adult onset of hypertension, at least in experimental animals, the exact mechanism of this action is not clear. Begg et al. $^{22}$ noted that at 10 weeks, the expression of angiotensin- $\mathrm{II}_{1 \mathrm{~A}}$ receptors and dopamine D3 receptors significantly increased in the hypothalamic tissue, whereas at 36 weeks the $\alpha 2 \mathrm{a}$ and $\beta 1$ adrenergic receptor expression was significantly reduced in the $\omega-3$ DEF group. These alterations in the expression of angiotensin- $\mathrm{II}_{1 \mathrm{~A}}$, dopamine D3, $\alpha 2 \mathrm{a}$ and $\beta 1$ adrenergic receptors suggest that they may have a role in the pathobiology of hypertension, or they may simply be bystander changes. One way of establishing their role in $\omega$-3-deficient hypertension is by studying the effect of angiotensin- $\mathrm{II}_{1 \mathrm{~A}}$, dopamine D3, $\alpha 2 \mathrm{a}$ and $\beta 1$ adrenergic receptor agonists and antagonists on blood pressure. It is not clear how this animal hypertension model responds to various antihypertensive drugs (that is, whether centrally acting antihypertensive drugs will be more effective than peripherally acting drugs, and if so, why and how). The possibility that lipid profile abnormalities in the form of high plasma cholesterol, triglycerides, lowdensity lipoprotein and very low-density lipoprotein, with low-high-density lipoprotein, (as observed in obesity, type 2 diabetes mellitus and some hypertensive subjects) could occur in this animal model needs to be studied with special emphasis on the functional capacity of high-density lipoprotein, as dysfunctional high-density lipoprotein is believed to be an important risk factor for atherosclerosis. It is important to know whether these animals have insulin resistance, which is observed in humans with hypertension.
Patients with uncontrolled essential hypertension have enhanced levels of $\mathrm{O}_{2}{ }_{2}^{-}, \mathrm{H}_{2} \mathrm{O}_{2}$, lipid peroxides, NADPH oxidase, ACE activity, and myeloperoxidase activity, and decreased half-life and/or concentrations of $\mathrm{PGI}_{2}$ and endothelial nitric oxide. ${ }^{2,12}$ It is worthwhile to investigate whether these abnormalities are present in the $\omega$-3-deficient hypertension model of Begg et al. ${ }^{22}$

Low-grade systemic inflammation, as evidenced by enhanced plasma levels of interleukin-6 (IL-6), tumor necrosis factor- $\alpha$ (TNF- $\alpha$ ) and high-sensitive CRP (hsCRP), occurs in patients with hypertension. ${ }^{34-38}$ Begg et al. ${ }^{22}$ have not measured plasma cytokines and hs-CRP levels in the $\omega$-3-deficient hypertensive animal model to know whether low-grade systemic inflammation is present. In all probability, inflammation would be present, as $\omega-3$ PUFAs are known to suppress the production of IL-6, TNF- $\alpha$ and myeloperoxidase activity. If this is true, and as plasma levels of hs-CRP, TNF- $\alpha$ and IL- 6 are also elevated in subjects with obesity, insulin resistance and type 2 diabetes, ${ }^{39,40}$ it remains to be seen whether $\omega$-3-deficient hypertensive animal models have some, if not all, of the features of the 


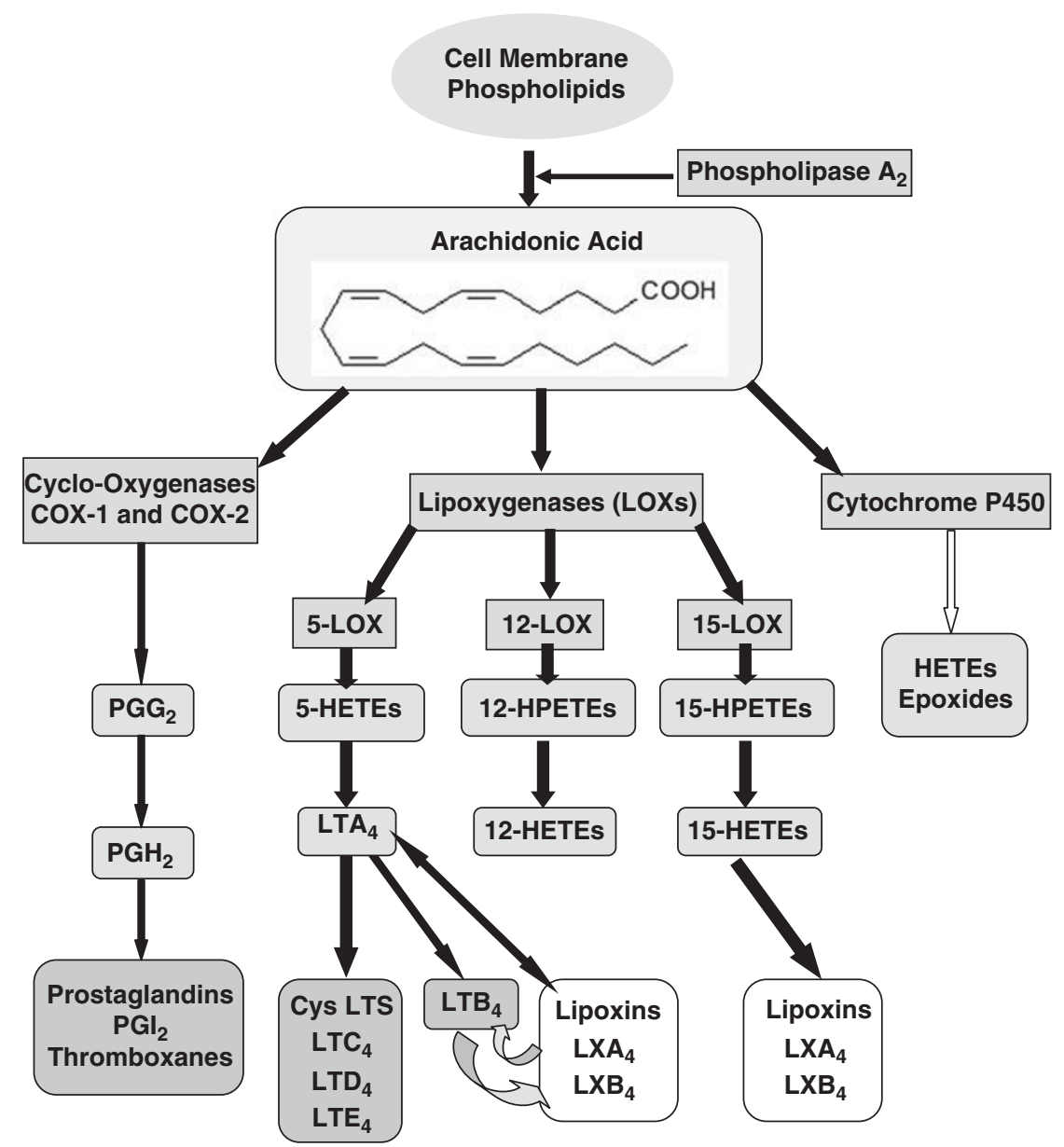

Figure 2 Metabolism of AA. Products similar to those formed from AA are also formed from EPA and DHA. A full color version of this figure is available at the Hypertension Research journal online.

Table 1 Polyunsaturated fatty acids composition of mature human breast milk

\begin{tabular}{lcc}
\hline Fatty Acid & & $\%, w t / w t$ \\
\hline Linoleic acid (LA) & $18: 2 \mathrm{n}-6$ & 10.76 \\
Gamma-linolenic acid (GLA) & $18: 3 \mathrm{n}-6$ & 0.16 \\
Dihomo-GLA (DGLA) & $20: 3 \mathrm{n}-6$ & 0.26 \\
Arachidonic acid (AA) & $20: 4 \mathrm{n}-6$ & 0.36 \\
Alpha-linolenic acid (ALA) & $18: 3 \mathrm{n}-3$ & 0.81 \\
Eicosapentaenoic acid (EPA) & $20: 5 \mathrm{n}-3$ & 0.04 \\
Docosapentaenoic acid (DPA) & $22: 5 \mathrm{n}-3$ & 0.17 \\
Docosapentaenoic acid (DHA) & $22: 6 \mathrm{n}-3$ & 0.22 \\
\hline
\end{tabular}

metabolic syndrome, and whether they have or would eventually develop peripheral insulin resistance, secondary hyperinsulinemia and type 2 diabetes mellitus.

Previously, Begg et al. ${ }^{25}$ reported that animals that received canola oil had lower body weight, less adiposity, lower plasma leptin levels, and consumed less food, whereas animals fed safflower oil+flaxseed oil also had lower, but less marked reductions in, adiposity and plasma leptin levels compared acids interact with each other to influence body weight, plasma leptin and, possibly, fatty acid composition and its metabolism in various tissues. It would have been interesting if the authors had studied hypothalamic Neuropeptide Y, serotonin, dopamine, pro-opiomelanocortin, melanocortins and acetylcholine levels in these studies, ${ }^{22,25}$ to determine the cause for the changes in the consumption of food and water, lower body weight, less adiposity and lower plasma leptin levels. Unfortunately, in both studies, ${ }^{22,25}$ the authors did not measure the fatty acid composition of the plasma, vascular tissue, kidneys, heart or liver to determine whether an $\omega-3$ PUFA deficiency was present in these tissues and in the brain. Such a study, along with the measurement of plasma NO, cytokines, NADPH oxidase (in the leukocytes and macrophages) and myeloperoxidase, would have provided a clue about the contribution of and interaction(s) among the various bioactive molecules involved in the pathobiology of hypertension in this animal model. 

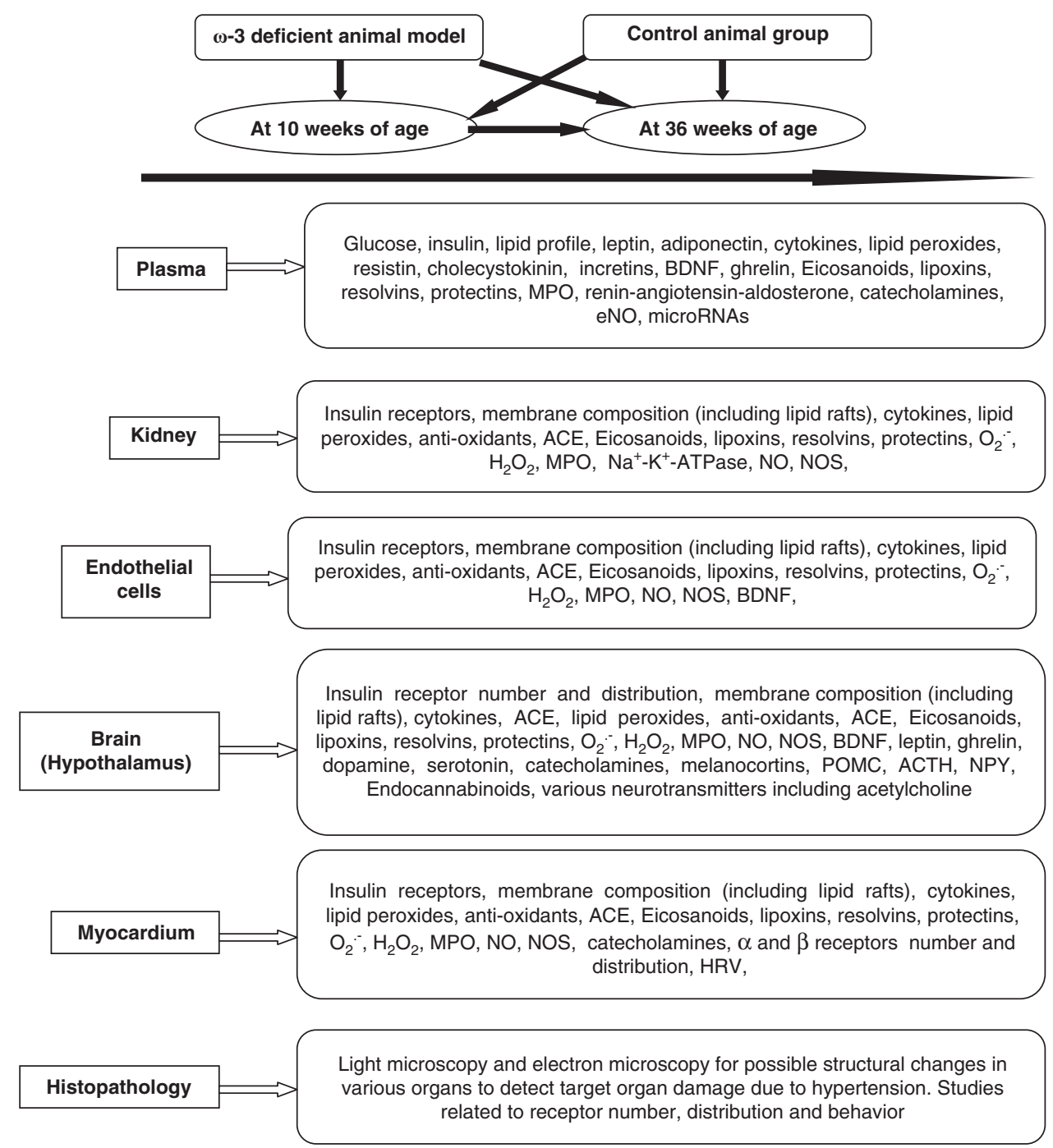

Figure 3 Scheme showing what studies can be performed in the $\omega$-3-deficient hypertensive animal model to elucidate the pathophysiological mechanisms of development of hypertension. It is necessary to study the incidence of non-alcoholic fatty liver disease in this animal model.

It is probably worthwhile to study the metabolism of PUFAs in the $\omega$-3-deficient hypertensive animal model, as shown in Figures 1 and 2. For instance, the pro-inflammatory products formed from AA, EPA and DHA (such as prostaglandins, leukotrienes and thromboxanes) and their anti-inflammatory products (lipoxins, resolvins and protectins in the plasma and kidney, vascular tissue, liver, myocardium and hypothalamus) need to be estimated in an $\omega$-3-deficient hypertensive animal model. As lipoxins, resolvins and protectins appear to be responsible for some, if not all, of the beneficial actions of AA/EPA/ DHA, a close look at their synthesis and action $^{41-43}$ needs special attention. Thus, studies that could be performed to answer some of the questions mentioned above in this $\omega$-3-deficient hypertensive animal model are depicted in Figure 3.

\section{ACKNOWLEDGEMENTS}

Dr UN Das is in receipt of the Ramalingaswami Fellowship from the Department of Biotechnology, New Delhi, India during the tenure of this study. A part of this work is supported by a grant from the Defense Research and Development Organization (DRDO), New Delhi, India.

1 Conen D, Ridker PM, Mora S, Buring JE, Glynn RJ. Blood pressure and risk of developing type 2 diabetes mellitus: The Women's Health Study. Eur Heart J 2007; 28: 2937-2943.

2 Das UN. Essential fatty acids and their metabolites in the context of hypertension. Hypertens Res 2010; 33: 782-785.

3 Reaven GM. Insulin resistance: the link between obesity and cardiovascular disease. Med Clin North Am 2011; 95: 875-892.

4 O'Rahilly S, Hattersley A, Vaag A, Gray H. Insulin resistance as the major cause of impaired glucose tolerance: a self-fulfilling prophecy? Lancet 1994; 344: 585-589.
5 Schalkwijk CG, Stehouwer CD. Vascular complications in diabetes mellitus: the role of endothelial dysfunction. Clin Sci (Lond) 2005; 109: 143-159.

6 Rajkumar C, Mensah R, Meeran K, Armstrong S, Bulpitt CJ. Peripheral arterial compliance is lower in Afro-Caribbeans compared to white Caucasians with type 2 diabetes after adjustment for blood pressure. J Hum Hypertens 1999; 13: 841-843.

7 Mahfoud F, Schlaich M, Kindermann I, Ukena C, Cremers B, Brandt MC, Hoppe UC, Vonend O, Rump LC, Sobotka PA, Krum H, Esler M, Böhm M. Effect of renal sympathetic denervation on glucose metabolism in patients with resistant hypertension: a pilot study. Circulation 2011; 123: 1940-1946.

8 Park S, Ahn IS, Kim da S. Central infusion of leptin improves insulin resistance and suppresses beta-cell function, but not beta-cell mass, primarily through the sympathetic nervous system in a type 2 diabetic rat model. Life Sci 2010; 86: 854-862.

9 Savoy YE, Ashton MA, Miller MW, Nedza FM, Spracklin DK, Hawthorn $\mathrm{MH}$, Rollema $\mathrm{H}$, Matos FF, HajosKorcsok E. Differential effects of various typical and atypical antipsychotics on plasma glucose and insulin levels in the mouse: evidence for the involvement of sympathetic regulation. Schizophr Bull 2010; 36: 410-418. 
10 Esler M. The sympathetic nervous system through the ages: from Thomas Willis to resistant hypertension. Exp Physiol 2011; 96: 611-622.

11 Lambert E, Sari Cl, Dawood T, Nguyen J, McGrane M, Eikelis N, Chopra R, Wong C, Chatzivlastou K, Head G, Straznicky N, Esler M, Schlaich M, Lambert G. Sympathetic nervous system activity is associated with obesity-induced subclinical organ damage in young adults. Hypertension 2010; 56: 351-358.

12 Kumar KV, Das UN. Are free radicals involved in the pathobiology of human essential hypertension? Free Radical Res Commun 1993; 19: 59-66.

13 Das UN. Long-chain polyunsaturated fatty acids interact with nitric oxide, superoxide anion, and transforming growth factor-b to prevent human essential hypertension. Eur J Clin Nutr 2003; 58 (2): 195-203.

14 Suryaprabha P, Das UN et al. Free Radicals, lipid peroxidation and essential fatty acids in uncontrolled essential hypertension. Prostaglandins Leukot Essen Fatty Acids 1990; 41: 27-33.

15 Félétou M, Vanhoutte PM. Endothelium-derived hyperpolarizing factor: where are we now? Arterioscler Thromb Vasc Biol 2006; 26: 1215-1225.

16 Ozkor MA, Quyyumi AA. Endothelium-derived hyperpolarizing factor and vascular function. Cardiol Res Pract 2011; 2011: 156146.

17 Fleming I. Epoxyeicosatrienoic acids, cell signaling and angiogenesis. Prostaglandins Other Lipid Mediat 2007 82: 60-67.

18 Arnold C, Konkel A, Fischer R, Schunck W-H. Cytochrome P450-dependent metabolism of $\omega-6$ and $\omega-3$ long-chain polyunsaturated fatty acids. Pharmacological Rep 2010; 62: 536-547.

19 Fer M, Dréano Y, Lucas D, Corcos L, Salaün J-P, Berthou F, Amet Y. Metabolism of eicosapentaenoic and docosahexaenoic acids by recombinant human cytochromes P450. Arch Biochem Biophys 2008; 471: 116-125.

20 Fer M, Corcos L, Dréano Y, Plée-Gautier E, Salaün J-P, Berthou F, Amet Y. Cytochromes P450 from family 4 are the main omega hydroxylating enzymes in humans: CYP4F3B is the prominent player in PUFA metabolism. J Lipid Res 2008; 49: 2379-2389.

21 Arnold C, Markovic M, Blossey K, Wallukat G, Fischer $\mathrm{R}$, Dechend R, Konkel A, von Schacky C, Luft FC, Muller DN, Rothe M, Schunck WH. Arachidonic acid- metabolizing cytochrome P450 enzymes are targets of \{omega\}-3 fatty acids. J Biol Chem 2010; 285: 32720-32733.

22 Begg DP, Puskás LG, Kitajka K, Ménesi D, Allen AM, Li D, Mathai ML, Shi JR, Sinclair AJ, Weisinger RS. Hypothalamic gene expression in $\omega-3$ PUFA-deficient male rats before, and following, development of hypertension. Hypertens Res 2012; 35: 381-387.

23 Weisinger HS, Armitage JA, Sinclair AJ, Vingrys AJ, Burns PL, Weisinger RS. Perinatal omega- 3 fatty acid deficiency affects blood pressure later in life. Nat Med 2001; 7: 258-259.

24 Li D, Weisinger HS, Weisinger RS, Mathai M, Armitage JA, Vingrys AJ, Sinclair AJ. Omega 6 to omega 3 fatty acid imbalance early in life leads to persistent reductions in DHA levels in glycerophospholipids in rat hypothalamus even after long-term omega 3 fatty acid repletion. Prostaglandins Leukot Essent Fatty Acids 2006; 74: 391-399.

25 Begg DP, Sinclair AJ, Stahl LA, Premaratna SD, Hafandi A, Jois M, Weisinger RS. Hypertension induced by o-3 polyunsaturated fatty acid deficiency is alleviated by a-linolenic acid regardless of dietary source. Hypertens Res 2010; 33: 808-813.

26 Armitage JA, Pearce AD, Sinclair AJ, Vingrys AJ, Weisinger RS, Weisinger HS. Increased blood pressure later in life may be associated with perinatal n-3 fatty acid deficiency. Lipids 2003; 38: 459-464.

27 Begg DP, Sinclair AJ, Stahl LA, Garg ML, Jois M, Weisinger RS. Dietary protein level interacts with omega-3 polyunsaturated fatty acid deficiency to induce hypertension. Am J Hypertens 2010; 23 . 125-128.

28 Mitasikova M, Smidova S, Macsaliova A, Knezl V, Dlugosova K, Okruhlicova L, Weismann P, Tribulova $\mathrm{N}$. Aged male and female spontaneously hypertensive rats benefit from n-3 polyunsaturated fatty acids supplementation. Physiol Res 2008; 57(Suppl 2): S39S48.

29 Forsyth JS, Willatts P, Agostoni C, Bissenden J, Casaer $P$, Boehm G. Long chain polyunsaturated fatty acid supplementation in infant formula and blood pressure in later childhood: follow up of a randomised controlled trial. BMJ 2003; 326: 953.

30 Taittonen L, Nuutinen M, Turtinen J, Uhari M. Perinatal factors in predicting later blood pressure among chil- dren: cardiovascular risk in young Finns. Pediatr Res 1996; 40: 627-632.

31 Wilson AC, Forsyth JS, Greene SA, Irvine L, Hau C, Howie PW. Relation of infant diet to childhood health: seven year follow up of cohort in Dundee infant feeding study. BMJ 1998; 316: 21-25.

32 Singhal A, Cole TJ, Lucas A. Early nutrition in preterm infants and later blood pressure: two cohorts after randomized trials. Lancet 2001; 357: 413-419.

33 Baur LA, O'Connor J, Pan DA, Kriketos AD, Storlien LH. The fatty acid composition of skeletal muscle membrane phospholipids: its relationship with the type of feeding and plasma glucose levels in young children. Metabolism 1998; 47: 106-112.

34 Das UN. Long-chain polyunsaturated fatty acids interact with nitric oxide, superoxide anion, and transforming growth factor- $\beta$ to prevent human essential hypertension. Eur J Clin Nutr 2003; 58: 195-203.

35 Das UN. Hypertension as a low-grade systemic inflammatory condition that has its origins in the perinatal period. J Assoc Physicians India 2006; 54: 133-142.

36 Arun Kumar C, Das UN. Lipid peroxides, anti-oxidants and nitric oxide in patients with pre-eclampsia and essential hypertension. Med Sci Monitor 2000; 6: 901-907.

37 Das UN. Nutritional factors in the pathobiology of human essential hypertension. Nutrition 2001; 17 : 337-346.

38 Das UN, Repossi G, Dain A, Eynard AR. L-arginine, NO and asymmetrical dimethylarginine in hypertension and type 2 diabetes. Frontiers BioSci 2011; 16: 13-20.

39 Barzilay JI, Abraham L, Heckbert SR, Cushman M, Kuller LH, Resnick HE, Tracy RP. The relation of markers of inflammation to the development of glucose disorders in the elderly. Diabetes 2001; 50: 2384-2389.

40 Das UN. Risk of type 2 diabetes mellitus in those with hypertension. Eur Heart J 2008; 29: 952-953.

41 Das UN. Molecular Basis of Health and Disease. Springer: New York, 2011.

42 Das UN. Lipoxins, resolvins, protectins, maresins and nitrolipids: Connecting lipids, inflammation, and cardiovascular disease risk. Current Cardiovasc Risk Rep 2010; 4: 24-31.

43 Das UN. Lipoxins as biomarkers of lupus and other inflammatory conditions. Lipids Health Dis 2011; 10: 76. 